\title{
STATIN USE AND THE OVERALL SURVIVAL OF RENAL CELL CARCINOMA: A META-ANALYSIS
}

\author{
VOL 43 NO 4 DECEMBER 2020
}

Ping Wu, $M D^{1}$, Tingting Xiang, $M D^{2}$, Jing Wang, $M D^{3}$, Run Lv, $M D^{4}$, Yimeng Zhuang, $\mathrm{BD}^{4}$, Guangzhen $W u, \mathrm{PhD}^{5}$

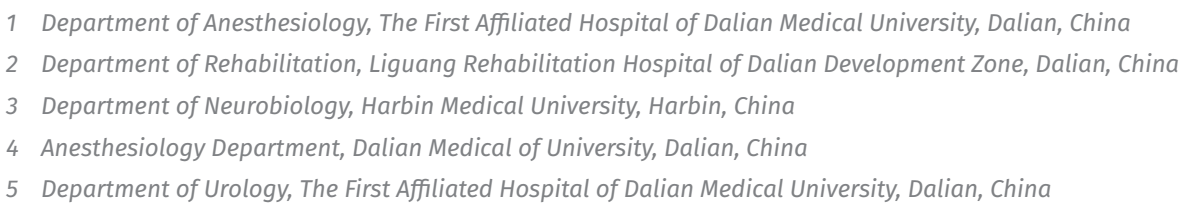

Department of Anesthesiology, The First Affiliated Hospital of Dalian Medical University, Dalian, China

Department of Rehabilitation, Liguang Rehabilitation Hospital of Dalian Development Zone, Dalian, China

Department of Neurobiology, Harbin Medical University, Harbin, China

4 Anesthesiology Department, Dalian Medical of University, Dalian, China

5 Department of Urology, The First Affiliated Hospital of Dalian Medical University, Dalian, China

Submitted 4th May 2020, Accepted 28th September 2020

Clin Invest Med. 2020;43(4):E17-23. DOI: 10.25011/cim.v43i4.34908

\section{ABSTRACT}

Purpose: Statins are commonly prescribed drugs that reduce cholesterol levels and the risk of cardiovascular and cerebrovascular events. Clinical studies have shown that statins also possess cancer-preventive properties. Two studies have reported that statins also possess cancer-preventive properties; however, whether statins improve the prognosis of patients with renal cell carcinoma is still unclear. In this study, we used meta-analysis to evaluate the association between statin use and overall survival risk in patients with renal cell carcinoma.

Methods: Published studies on statin-treated renal cell carcinoma were retrieved from PubMed, Embase, The Cochrane Library, China National Knowledge Infrastructure and Wanfang databases from inception to July 2019. The relevant data were extracted and a meta-analysis was performed using Cochrane Review Manager (RevMan 5.3) software.

Results: Data from five studies, which reported on 5,299 patients, were analysed. The application of statins showed no effects on the overall survival of patients with renal cell carcinoma compared with the control group (OR $=1.07,95 \% \mathrm{Cl}: 0.77$ to $1.49, P=0.68$ ).

Conclusions: The findings of this meta-analysis suggest that statin application does not affect the overall survival of patients with renal cell carcinoma.

Correspondence to: Guangzhen Wu, wuguang0613@hotmail.com

\section{INTRODUCTION}

Statins have been used extensively for the treatment of hypercholesterolemia and cardiovascular events. They act by inhibiting 3-hydroxy-3-methylglutaryl coenzyme A (HMG-COA) reductase to reduce cholesterol levels [1]. Statins are among the most commonly prescribed medications worldwide, and their use has gradually increased over the past decade.

Recently, an increasing number of studies have indicated that statins exhibit anti-tumor properties in vitro and in vivo. Apostolova et al. reported that statins reduced angiogenesis, promoted apoptosis and inhibited the cellular signalling pathways involved in tumor growth and metastasis [1]. Iannelli et al. demonstrated that statins significantly inhibited tumor proliferation in patients [2]. In some observational clinical studies, statins have been indicated to improve survival outcomes in prostate, colorectal, and breast cancer patients [3,4]. Several related clinical trials have investigated the effects of statins on survival outcomes. However, the limited sample size rendered the results inconclusive [5]. Previous studies have found that the application of statins can improve the overall postoperative risk of patients with renal cell carcinoma (RCC) [6,7], while other observational studies showed equivocal results or demonstrated conflicting results $[8,9]$.

A meta-analysis on the association of statin application and the overall survival (OS) of patients with RCC has not previously been reported. In this study, we performed 
a meta-analysis to investigate the use of statins and their effects on the OS of patients with RCC during the postoperative period.

\section{METHODS}

\section{Search strategy}

We conducted a computerized search on PubMed, Embase, Cochrane Library, CNKI, and Wanfang databases from inception to July 2019. The search terms included the following: ((Statins OR Statin OR HMG-Co A reductase inhibitors OR Atorvastatin OR Cerivastatin OR Fluvastatin OR Lova-statin OR Pravastatin OR Rosuvastatin OR Simvastatin)) AND (cancer OR neoplasm OR malignancy) AND (renal or kidney), and were sorted by best match. The corresponding references were retrieved via hand searching. When necessary, we obtained research data by contacting the corresponding author. The languages of the articles were limited to English and Chinese, and we included only human research. All of our data investigation and collection processes were in line with the Declaration of Helsinki.

\section{Selection of eligible studies}

The criteria for eligible studies were defined as studies that 1) focused on statins-such as atorvastatin, cerivastatin, fluvastatin, lovastatin, pravastatin, rosuvastatin and simvastatin, 2) comprised pathology that was confirmed as a case of RCC, 3 ) assessed the effect of statin use on the risk of RCC cases, 4) contained enough survival information and 5) were case-control studies, cohort studies and RCT statin therapy studies. The exclusion criteria comprised studies that 1) focused on non-primary RCC, 2) had no control group or treated patients with other drugs besides statins, 3) were case reports and 4) did not contain the necessary survival information, especially the OS. We chose the latest or most complete studies when multiple articles contained overlapping data. At least two authors evaluated the articles that met these criteria to assess the appropriateness of their inclusion.

\section{Methodological quality assessment}

Two authors independently assessed the quality of the literature using the Newcastle-Ottawa scale [10]. A semi-quantitative assessment of literature quality was processed using a star system based on three dimensions, including selection, comparability and exposure [11]. Each study was scored 0-9, with higher scores indicating higher quality studies. Articles with fewer than five points were determined to represent a high risk of bias, and a score higher than six indicated high quality $[12,13]$. When the two evaluators disagreed, they resolved it by discussing the matter with a third author.

\section{Data extraction}

The primary outcome of this meta-analysis was the OS rate, which refers to the proportion of the population in the treatment group that was still alive after 3-5 years. Three investigators conducted the data extraction: two investigators extracted data from the eligible studies using a predefined data collection form and the third investigator resolved any disagreements or uncertainty. The primary information contained the publication year, first author's name, total number of patients, country, type of study, collecting case time, metastatic RCC cases, median follow-up (months) and the OS rate. The study information was recorded using a standard form.

\section{Statistical analysis}

Meta-analyses were performed using Cochrane Review Manager (RevMan) software version 5.3. Count data were analyzed through the odds ratio (OR) and $95 \%$ confidence interval $(95 \% \mathrm{Cl})$ to find the quantity needed to have a therapeutic effect. Statistical heterogeneity among these studies was determined via the $\mathrm{I}^{2}$ statistic, $I^{2}=100 \% \times(Q-d f) / Q$, ranging from $0-100 \%$. In this equation, $\mathrm{Q}$ represented the Cochran's heterogeneity statistic, and df represented the degrees of freedom $\left(1^{2}<25 \%\right.$, no heterogeneity; $25 \%<1^{2}<50 \%$, moderate heterogeneity; $I^{2}>50 \%$, high heterogeneity) [14]. For $I^{2}$, a value of $>50 \%$ was considered to be a measure of heterogeneity and was analyzed via the random effect model; for $\mathrm{l}^{2}<50 \%$, the fixed-effects model was applied. The subgroup analyses and sensitivity analyses were performed first, and publication bias was assessed using funnel plots. $P$ values of $<0.05$ represented statistically significant differences.

\section{Ethical approval}

This article does not require any studies on human participants or animals to be performed by any of the authors.

\section{RESULTS}

\section{Included studies}

Of the 436 articles identified after the initial literature search, 275 were excluded based on their titles and abstracts, which were unrelated to our study design. The remaining 161 full-text articles were assessed for eligibility. Five case-control studies (Figure 1), which reported on 5,299 patients with RCC using statins, were carefully selected based on the above inclusion and exclusion criteria for our meta-analysis. The articles by Viers et al. [15-19] were not identified using the computerized search strategy, but by manual searching. 
FIGURE 1.

FLOW CHART OF STUDY SELECTION.

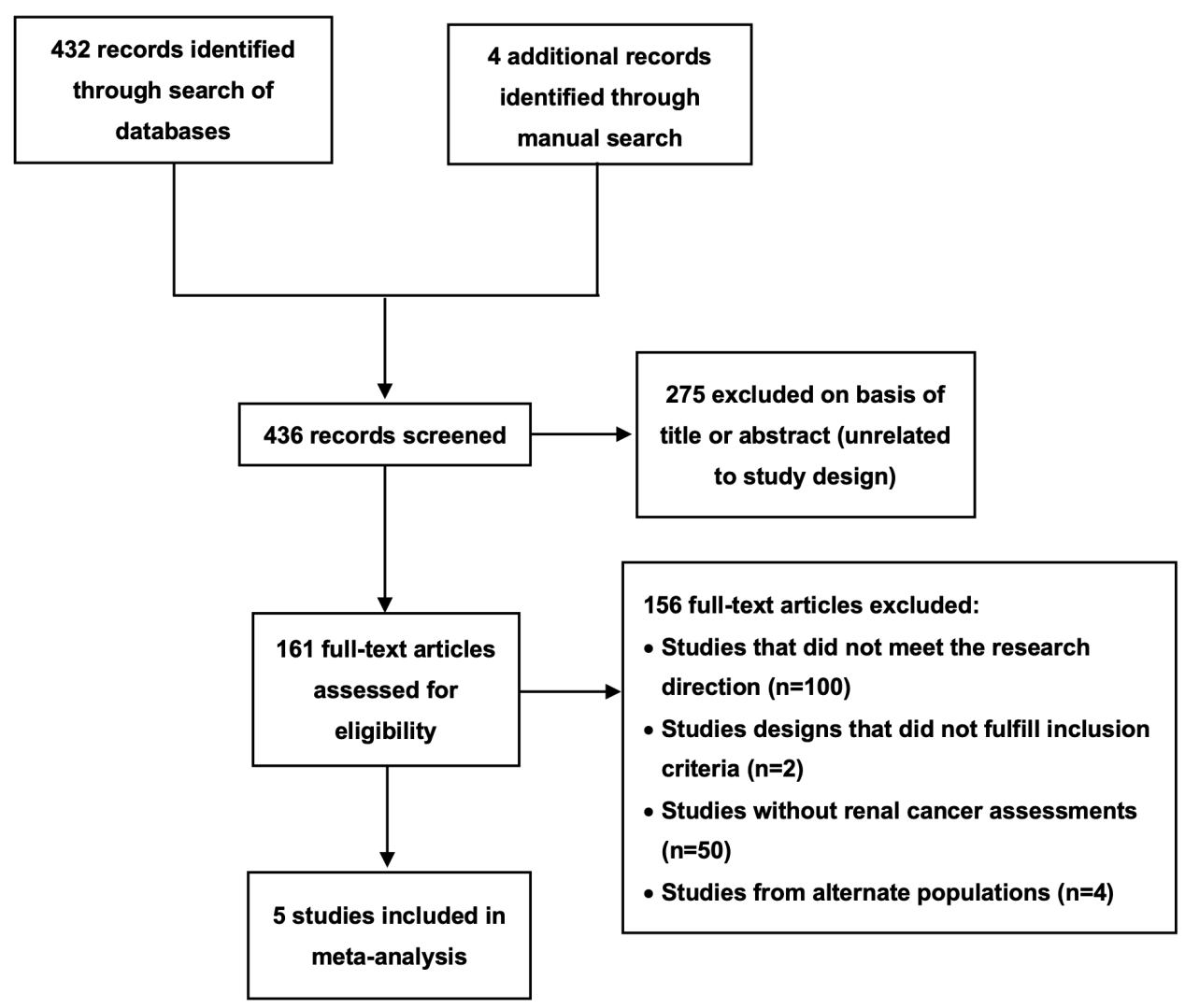

reasonably good quality according to the aforementioned criteria (green or "+" represented a low risk of bias; red or "-" represented a high risk of bias; and yellow or "?" represented an unclear risk of bias) (Figure 2). The basic characteristics and quality assessment of the included studies are shown in Table 1.

Association between statin application and the OS of patients with RCC

Five studies compared the OS of patients with RCC between the statin and control groups. Meta-analysis of the data showed that the application of statins did not affect the OS of patients diagnosed with $\mathrm{RCC}(\mathrm{OR}=1.07$, $95 \%$ IC: 0.77 to $1.49, p=0.68$ ). The data also showed significant heterogeneity among the five studies $\left(\mathrm{Tau}^{2}=0.1\right.$, $\mathrm{Chi}^{2}=15.87, \mathrm{df}=4, \mathrm{I}^{2}=75 \%, p=0.003$ ) (Figure 3).

Heterogeneity analysis and sensitivity analysis

Due to the significant heterogeneity of the present meta-analyses, a subgroup Study characteristics and methodological quality assessment

Quality assessment of the included studies was conducted according to the Newcastle-Ottawa scale. The study scores were as follows: seven points for two of the cases $[16,18]$; and six points for three of the cases $[9,10,17]$, which indicated that the observational studies were of

\section{FIGURE 2.}

\section{BIAS RISK ASSESSMENT OF SELECTED ARTICLES.}

\begin{tabular}{|c|c|c|c|c|c|}
\hline 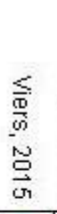 & 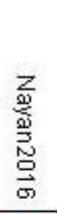 & 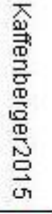 & 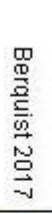 & 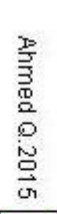 & \\
\hline+ & 0 & $\odot$ & $\odot$ & + & Random sequence generation (selection bias) \\
\hline+ & $\odot$ & $\odot$ & $\odot$ & $\odot$ & Allocation concealment (selection bias) \\
\hline ? & $\odot$ & $\odot$ & $\odot$ & $\odot$ & Blinding of participants and personnel (performance bias \\
\hline$\odot$ & $\odot$ & $\odot$ & $\odot$ & $\odot$ & Blinding of outcome assessment (detection bias) \\
\hline$\sim$ & $\odot$ & $\odot$ & $\odot$ & ? & Incomplete outcome data (attrition bias) \\
\hline 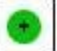 & $\cdot$ & $\odot$ & $\odot$ & $\odot$ & Selective reporting (reporting bias) \\
\hline+ & $\odot$ & $\sim$ & $\odot$ & 0 & Other bias \\
\hline
\end{tabular}
analysis and a sensitivity analysis were performed. A subgroup analysis of the sample size bounded by 500 and 1000 was performed. The results showed significant heterogeneity, which indicated that the sample size was not a potential source of heterogeneity (sample size: 500 $\leq n<1000 ; \mathrm{Tau}^{2}=0.15, \mathrm{Chi}^{2}=8.88, \mathrm{df}=2, \mathrm{I}^{2}=77 \%, p=$ 0.01; sample size: $\mathrm{n}>1000$; $\mathrm{Tau}^{2}=0.1, \mathrm{Chi}^{2}=15.87, \mathrm{df}=$ $4, I^{2}=75 \%, p=0.003$ ) (Figure 4). We next analyzed the subgroup according to the impact factor (IF), which was bounded by 3 . We found that the impact factor was the source of heterogeneity, of which the IF $\leq 3$ group was $\mathrm{Tau}^{2}=0.00, \mathrm{Chi}^{2}=0.14, \mathrm{df}=1, \mathrm{I}^{2}=0 \%, p=0.71$; the IF $>3$ group was $\mathrm{Tau}^{2}=0.01, \mathrm{Chi}^{2}=2.83, \mathrm{df}=2, \mathrm{I}^{2}=29 \%, p=0.24$ (Figure 5). This analysis suggests that the IF may account for the heterogeneity.

We further confirmed the stability of the data by doing a sensitivity analysis. No significant variation was found by excluding any of these five studies. However, after excluding two studies with IF $\leq 3$, there was no study heterogeneity. These findings suggest that the studies by Haddad et al. and Berquist et al., both of which had an IF of $\leq 3$, contributed most to the heterogeneity among the five studies (Figure 6). Finally, these results indicated that there was no significant publication bias, as can be seen in the funnel plot in Figure 7. 
TABLE 1.

\section{CHARACTERISTICS OF THE STUDIES* INCLUDED IN THE META-ANALYSIS}

\begin{tabular}{|c|c|c|c|c|c|c|c|}
\hline Author & Year & $\begin{array}{c}\text { Total number of } \\
\text { patients }\end{array}$ & $\begin{array}{l}\text { Country where study } \\
\text { was conducted }\end{array}$ & $\begin{array}{c}\text { Collecting case } \\
\text { dates }\end{array}$ & $\begin{array}{c}\text { Metastatic renal cell } \\
\text { carcinoma cases }\end{array}$ & $\begin{array}{l}\text { Median follow-up } \\
\text { (month) }\end{array}$ & $\begin{array}{c}\text { Newcastle-Ottawa } \\
\text { scale score }\end{array}$ \\
\hline Ahmed & 2015 & 850 & United States & 2000 to 2012 & yes & 25 & 7 \\
\hline Kaffenberger & 2015 & 916 & United States & 2000 to 2010 & yes & 42.5 & 6 \\
\hline Viers & 2015 & 2,357 & United States & 1995 to 2009 & no & 24 & 7 \\
\hline Nayan & 2016 & 893 & Canada & 2000 to 2014 & no & $\mathrm{N} / \mathrm{S}$ & 6 \\
\hline Berquist & 2017 & 283 & United States & 1995 to 2005 & yes & 68 & 6 \\
\hline
\end{tabular}

*All studies were retrospective.

FIGURE 3.

META-ANALYSIS OF THE EFFECTS OF STATIN USE ON OVERALL SURVIVAL IN PATIENTS WITH RENAL CELL CARCINOMA.

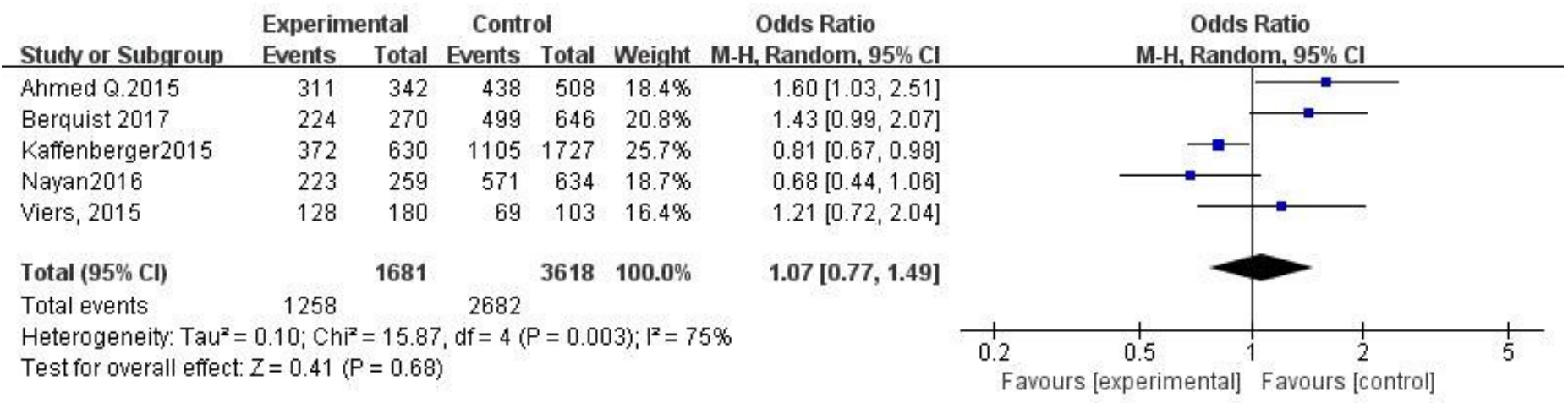

\section{DISCUSSION}

This is the first published meta-analysis on the correlation between the use of statins and the OS of RCC patients. We found that the application of statins has no effect on the OS of patients with RCC.

For the past few decades, the role of statins in the development of cancer has become better understood. The meta-analysis conducted by Islam et al. showed no association between statins and a breast cancer prognosis [20]. Similarly, Hamada et al.'s meta-analysis showed no reduction in pancreatic cancer risk among statin users as compared with non-users [21]. A meta-analysis conducted by Pradelli et al., which showed an inverse association between statin use and liver cancer-related mortality, showed a $40 \%$ reduction in the risk of cancer associated with statin use, regardless of the duration of statin exposure [22].

Although statins have been reported to inhibit the proliferation and progression of RCC, and have also been shown to induce apoptosis, our results showed that statin use has no definitive effect on RCC and related OS risks [23,24]. However, the existing studies that reported on the inhibitory effect of statins on RCC were limited to in vitro data and it is possible that in vivo and in vitro experiments may show different outcomes. Furthermore, statins are known to be selectively taken up by the liver and less than $5 \%$ of a given dose reaches systemic circulation. Based on their selective hepatic uptake and low systemic availability, the usefulness of statins as chemopreventive agents for kidney cancer is questionable $[25,26]$. Moreover, one of our recent studies [27] has shown that the lipid metabolism of renal cancer is different from that of other tumors. In renal cancer, the expression of a cholesterol synthase protein, such as HMG-CoA reductase (HMGCR), was significantly lower than that of normal adjacent tissues [27]. This indicated that cholesterol increases in RCC but is not the source of the HMGCR-mediated cholesterol synthesis pathway. The main mechanism of action of statins is via the down-regulation of HMGCR. We can conclude that these above mentioned factors-low availability of statins and lower expression of HMGCR in renal cancer-may account for the failure effect of statins on RCC.

Despite the limited number of published articles used for this study and the low risk of bias found in them, our meta-analysis suggests that statin use in patients 
FIGURE 4.

FOREST PLOT: SUBGROUP ANALYSES BASED ON SAMPLE SIZE.

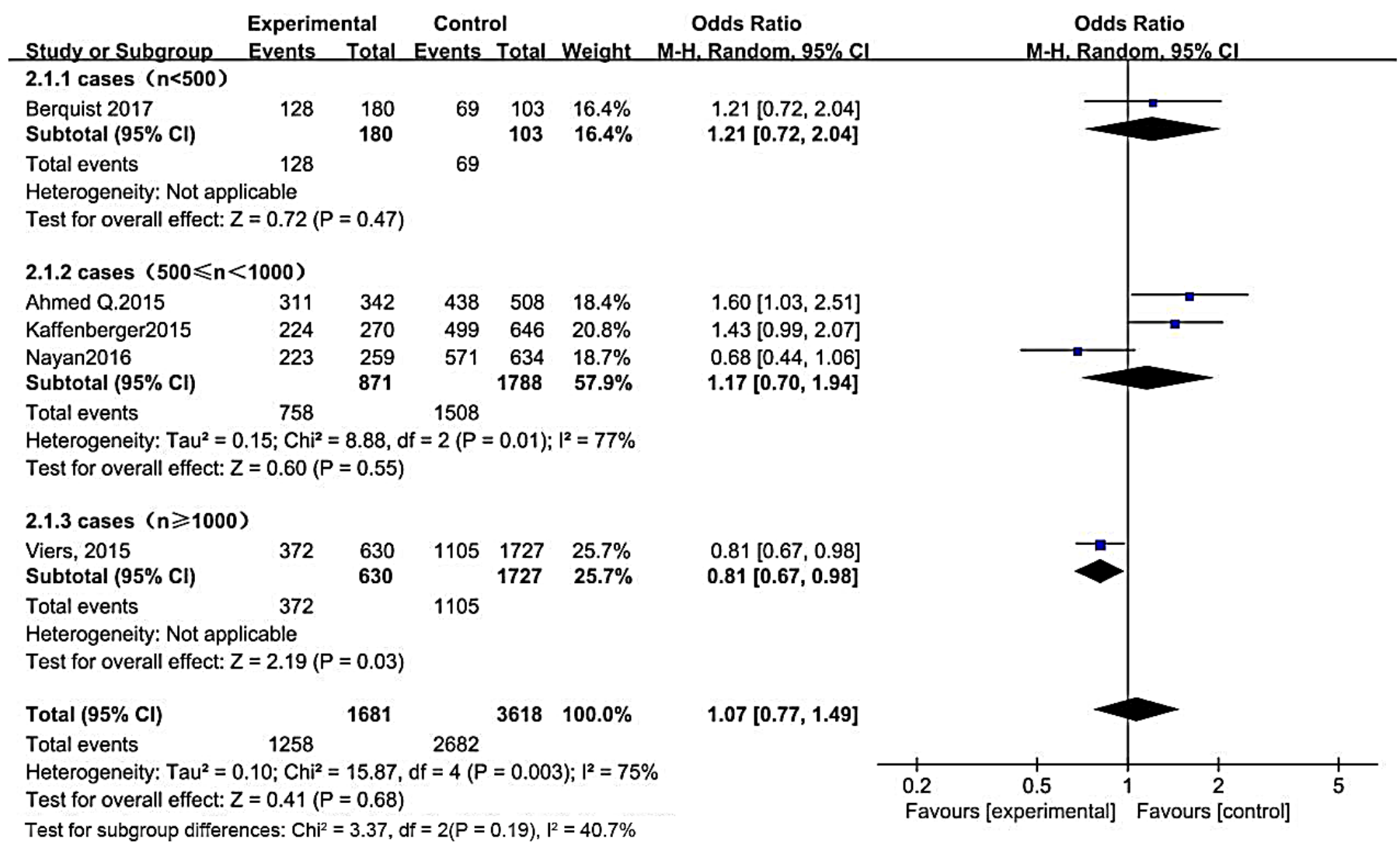

FIGURE 5.

FOREST PLOT: SUBGROUP ANALYSES BASED ON IMPACT FACTOR.

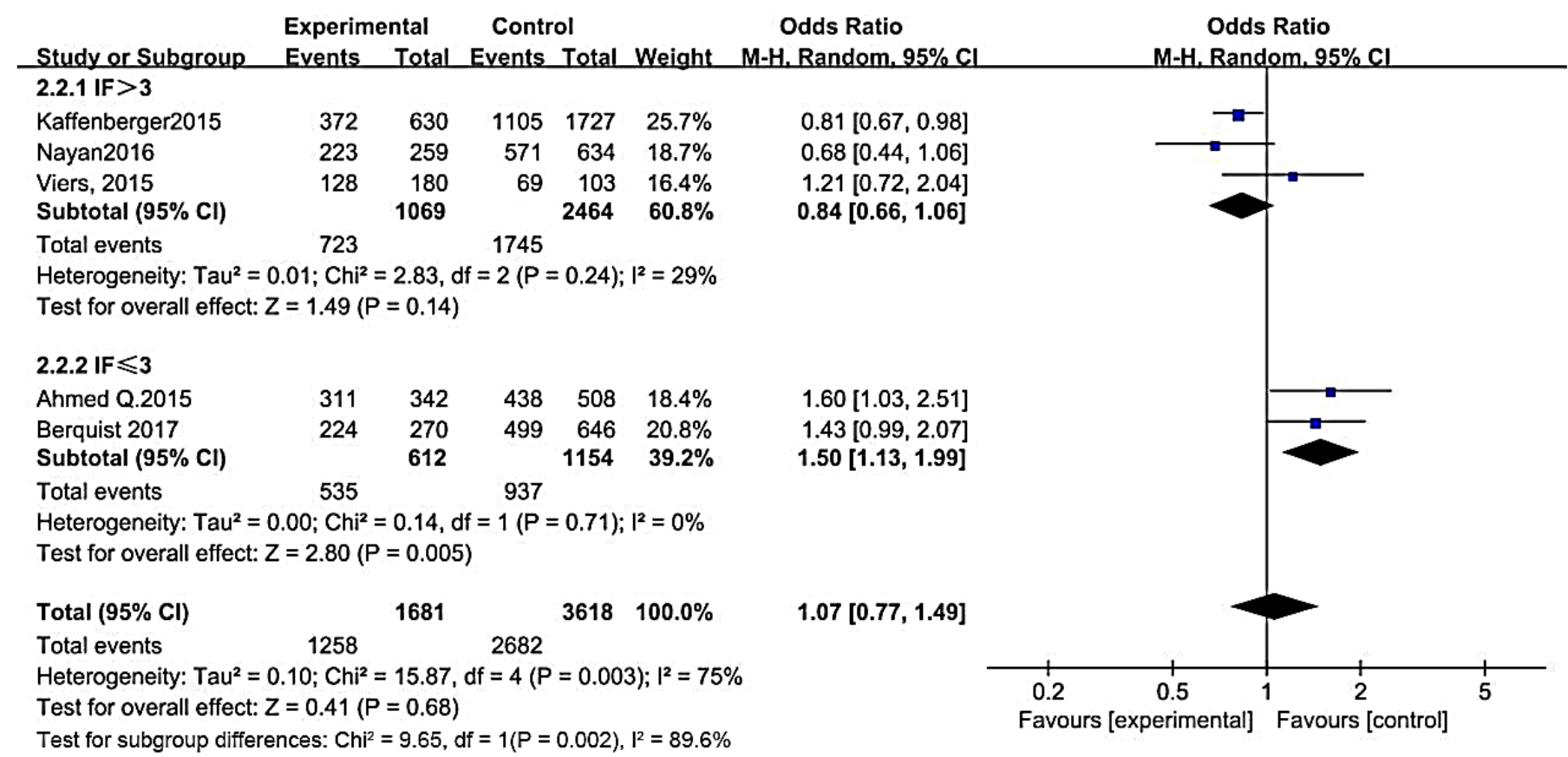


FIGURE 6 .

FOREST PLOT: SENSITIVITY ANALYSES OF STATIN USE AND OVERALL SURVIVAL OF RENAL CELL CARCINOMA.

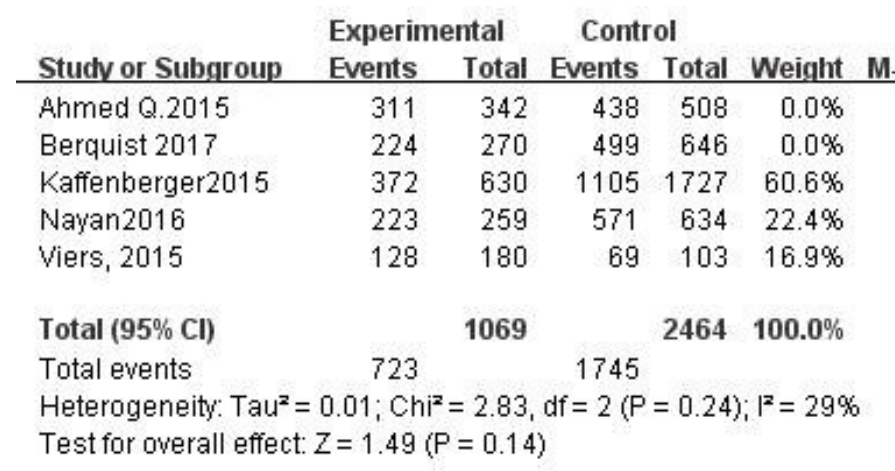

\section{FIGURE 7.}

\section{FUNNEL PLOT ANALYSES OF POTENTIAL PUBLICATION}

BIAS.

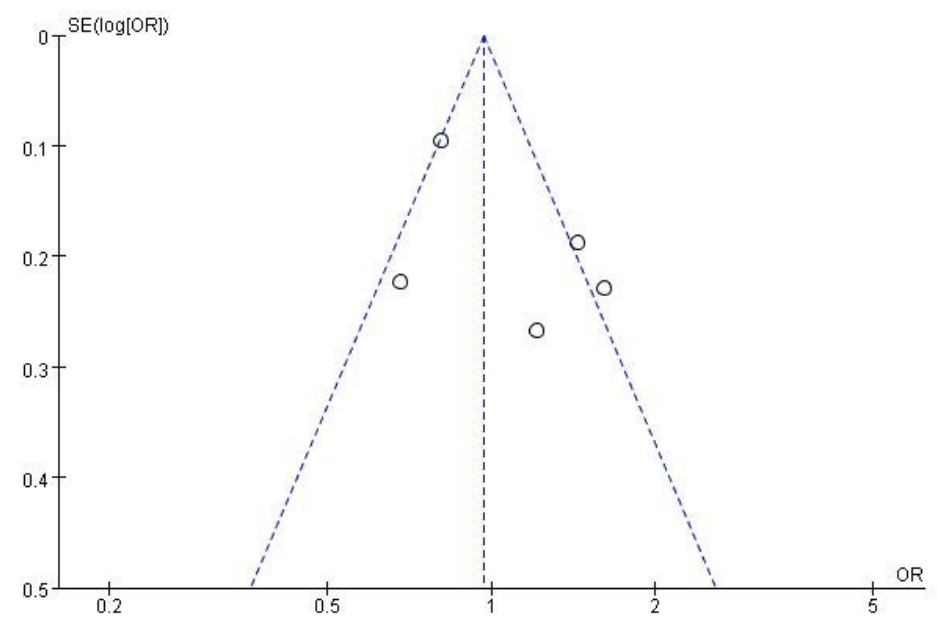

diagnosed with RCC does not improve the OS rate during the postoperative period.

Our meta-analysis has several limitations. First, we did not search for unpublished studies or original data. Second, we did not perform a group analysis of the duration of statins' action, the dose of the drug and the evaluation time of the OS. Finally, we need to continue to evaluate the long-term effects of statins, as cancer is an endpoint that requires at least 10 years of follow-up.

In summary, the results of this meta-analysis indicated that the use of statins is not associated with OS after RCC. More research is needed, especially randomized controlled trials.
Odds Ratio

$0.81[0.67,0.98]$

$0.68[0.44,1.06]$

$1.21[0.72,2.04]$

$0.84[0.66,1.06]$
Odds Ratio

M-H, Random, $95 \% \mathrm{Cl}$

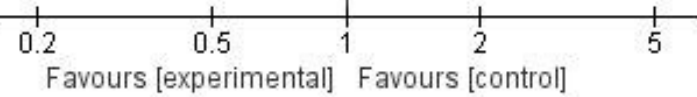

\section{REFERENCES}

1. Apostolova SN, Toshkova RA, Momchilova AB, Tzoneva RD. Statins and Alkylphospholipids as New Anticancer Agents Targeting Lipid Metabolism. Anticancer Agents Med Chem. 2016;16(12):1512-22.

2. Iannelli F, Lombardi R, Milone M, Pucci B, De Rienzo S, Budillon A, et al. Targeting Mevalonate Pathway in Cancer Treatment: Repurposing of Statins. Recent patents on anti-cancer drug discovery. 2018;13(2):184-200.

3. Cardwell CR, Hicks BM, Hughes C, Murray LJ. Statin use after colorectal cancer diagnosis and survival: a population-based cohort study. J Clin Oncol. 2014;32(28):3177-83.

4. Murtola TJ, Peltomaa Al, Talala K, Määttänen L, Taari K, Tammela TLJ, et al. Statin Use and Prostate Cancer Survival in the Finnish Randomized Study of Screening for Prostate Cancer. Eur Urol Focus. 2017;3(2-3):212-20.

5. Gazzerro P, Proto MC, Gangemi G, Malfitano AM, Ciaglia $\mathrm{E}$, Pisanti S, et al. Pharmacological actions of statins: a critical appraisal in the management of cancer. Pharmacol Rev. 2012;64(1):102-46.

6. Neumann E, Klaiber P, Freitag K, Schwab M, Schaeffeler E, Hennenlotter J, et al. Assessment of concomitant non-oncologic medication in patients with surgically treated renal cell carcinoma: impact on prognosis, cell-cycle progression and proliferation. J Cancer Res Clin Oncol. 2019;145(7):183543.

7. Khurana V, Caldito G, Ankem M. Statins might reduce risk of renal cell carcinoma in humans: case-control study of 500,000 veterans. Urology. 2008;71(1):118-22.

8. Pottegård A, Clark P, Friis S, Hallas J, Lund L. Long-term Use of Statins and Risk of Renal Cell Carcinoma: A Population-based Case-Control Study. Eur Urol. 2016;69(5):877-82.

9. Chiu HF, Kuo CC, Kuo HW, Lee IM, Lee CT, Yang CY. Statin use and the risk of kidney cancer: a population-based case-control study. Expert Opin Drug Saf. 2012;11(4):543-9.

10. Wells GA, Shea B, O'Connell D, Peterson J, Welch V, Losos $M$, et al. The Newcastle-Ottawa Scale (NOS) for assessing the quality of nonrandomized studies in meta-analyses. Ottawa Hosp Res Inst. 2013;3:1-4. 
11. Stang A. Critical evaluation of the Newcastle-Ottawa scale for the assessment of the quality of nonrandomized studies in meta-analyses. Eur J Epidemiol. 2010;25(9):603-5.

12. Yang $Y$, Zhang D, Feng N, Chen G, Liu J, Chen G, et al. Increased intake of vegetables, but not fruit, reduces risk for hepatocellular carcinoma: a meta-analysis. Gastroenterology. 2014;147(5):1031-42.

13. Veronese N, Cereda E, Solmi M, Fowler SA, Manzato E, Maggi S, et al. Inverse relationship between body mass index and mortality in older nursing home residents: a meta-analysis of 19,538 elderly subjects. Obes Rev. 2015;16(11):1001-15.

14. Higgins JP, Thompson SG, Deeks JJ, Altman DG. Measuring inconsistency in meta-analyses. Bmj. 2003;327(7414):557-60.

15. Viers BR, Houston Thompson R, Psutka SP, Lohse CM, Cheville JC, Leibovich BC, et al. The association of statin therapy with clinicopathologic outcomes and survival among patients with localized renal cell carcinoma undergoing nephrectomy. Urol Oncol. 2015;33(9):388.e11-8.

16. Nayan M, Finelli A, Jewett MAS, Juurlink DN, Austin PC, Kulkarni GS, et al. Statin use and kidney cancer outcomes: A propensity score analysis. Urol Oncol. 2016;34(11):487.e1-. e6.

17. Haddad AQ, Jiang L, Cadeddu JA, Lotan Y, Gahan JC, Hynan LS, et al. Statin Use and Serum Lipid Levels Are Associated With Survival Outcomes After Surgery for Renal Cell Carcinoma. Urology. 2015;86(6):1146-52.

18. Kaffenberger SD, Lin-Tsai O, Stratton KL, Morgan TM, Barocas DA, Chang SS, et al. Statin use is associated with improved survival in patients undergoing surgery for renal cell carcinoma. Urol Oncol. 2015;33(1):21.e11-21.e17.

19. Berquist SW, Lee HJ, Hamilton Z, Bagrodia A, Hassan AE, Beksaç AT, et al. Statin utilization improves oncologic and survival outcomes in patients with dyslipidemia and surgically treated renal cell carcinoma. Minerva Urol Nefrol. 2017;69(5):501-8.

20. Islam MM, Yang HC, Nguyen PA, Poly TN, Huang CW, Kekade $\mathrm{S}$, et al. Exploring association between statin use and breast cancer risk: an updated meta-analysis. Arch Gynecol Obstet. 2017;296(6):1043-53.

21. Hamada T, Khalaf N, Yuan C, Babic A, Morales-Oyarvide V, Qian ZR, et al. Statin use and pancreatic cancer risk in two prospective cohort studies. J Gastroenterol. 2018;53(8):95966.

22. Pradelli D, Soranna D, Scotti L, Zambon A, Catapano A, Mancia G, et al. Statins and primary liver cancer: a meta-analysis of observational studies. Eur J Cancer Prev. 2013;22(3):229-34.

23. Horiguchi A, Sumitomo M, Asakuma J, Asano T, Asano T, Hayakawa M. 3-hydroxy-3-methylglutaryl-coenzyme a reductase inhibitor, fluvastatin, as a novel agent for prophylaxis of renal cancer metastasis. Clin Cancer Res. 2004;10(24):8648-55.
24. Woodard J, Sassano A, Hay N, Platanias LC. Statin-dependent suppression of the Akt/mammalian target of rapamycin signaling cascade and programmed cell death 4 up-regulation in renal cell carcinoma. Clin Cancer Res. 2008;14(14):4640-9.

25. Hamelin BA, Turgeon J. Hydrophilicity/lipophilicity: relevance for the pharmacology and clinical effects of HMG-CoA reductase inhibitors. Trends Pharmacol Sci. 1998;19(1):26-37.

26. Rogers MJ. Statins: lower lipids and better bones? Nat Med. 2000;6(1):21-3.

27. Wu G, Wang Q, Xu Y, Li J, Zhang H, Qi G, et al. Targeting the transcription factor receptor LXR to treat clear cell renal cell carcinoma: agonist or inverse agonist? Cell Death Dis. 2019;10(6):416. 